\title{
Considering the Anchor Mission Strategy within the Competing "Regimes" of Higher Education Community Engagement
}

Daniel J. Bergen and Emily Sladek

\begin{abstract}
The concept of the anchor institution, and its subsequent mission, was first considered in the mid-1990s, a time during which the dominant academic culture of higher education was driven by the "public good regime." The decades since have seen the emergence of the publicengagement knowledge regime, and the academic capitalist regime. This article views the anchor mission strategy through the shifting and competing "regimes" of higher education and considers questions that might arise due to these shifts. Anticipating and understanding these questions increase the self-awareness critical to authentic engagement, lower the risk of reifying historical dynamics of power, privilege, and oppression, and elevate the potential for success in advancing the anchor strategy.
\end{abstract}

Keywords: markets; economy; regimes; engagement; anchor institutions

Increasingly, institutions of higher education are reconsidering their community roles more strategically. From research, to teaching, to local investments, and hiring, the advancement of community engagement has elevated institutional interest in the roles universities and colleges can play in their communities. Research clearly demonstrates that "colleges and universities have been called to collaborate with their broader communities to address societal issues and needs (Boyer, 1990; Campus Compact, n.d.; Carnegie, 2006; Weerts \& Sandman, 2010) and, at the same time, to participate more fully in the free-market economy (Nussbaum, 2010; Slaughter \& Rhoades, 2004)" (Giles, 2012). Institutions have therefore sought profit-generating opportunities (Slaughter \& Rhoades, 2004); political and/or funding pressures (Alperin, et. al, 2018); changing racial demographics; enlightened self-interest; or, all/some combination of the aforementioned strategies. Universities and colleges continue to be develop and refine strategies for local community engagement.

As one key strategy of local community engagement, the movement towards adopting an anchor mission strategy within the evolving spatial boundaries between institutions of higher education and their communities is necessarily fraught with complex tensions around economic and social power and privilege. For these purposes, advocates ought to shape the anchor mission strategy within the descriptive frameworks of the shifting paradigms, or "regimes," of higher education. This is to ensure the self-awareness critical to authentic engagement, and lower the risk of reifying historical dynamics of power, privilege, and oppression.

\section{The Anchor Mission Strategy}

Henry G. Cisneros, former Secretary of Housing and Urban Development, with contributions from Ira Harkavy, then Director for the Center of Community Partnerships at University of 
Pennsylvania, discussed the basic principles of the "anchor institution" in the 1995 essay, "The University and the Urban Challenge". In his essay, changing demographics, globalization, corporate migration to suburbs or overseas, social and economic immobility, create the urban context for what Cisneros considers, "the danger of becoming two nations: one with highly skilled, well-paid workers and professionals, and the other with a low-skilled, low- or even nowage, permanent underclass" (Cisneros, 1995). The solution that Cisneros proposes is to leverage the economic, and intellectual resources of local colleges and universities to revitalize cities, and "help create communities of opportunity."

In theory, by embracing this solution, collaborating with other locally identified anchors, and residents to develop community- and place-based approaches, resources and capacity can be better shared to accomplish collective goals. However, as Hodges and Dubb (2012) note, "anchor institution strategies may improve the quality of life in target neighborhoods, but without markedly improving the welfare of longtime neighborhood people-frequently low income and people of color - some of whom may move out of the neighborhoods due to increased rental values or rising property taxes". Subsequently, the anchor mission risks continuing to intensify strategies, or justify decisions, that further harm community relations, or fail to create generational wealth for people struggling the most. Instead, by understanding the strategy within the shifting and competing "regimes" of contemporary higher education, we can potentially mitigate the risks of harm, and elevate the potential for success.

\section{Competing "Regimes"}

In utilizing the term "regimes", we are specifically referring to Slaughter and Rhoades (2004) use of the competing "knowledge/learning regimes", and Saltmarsh and Hartley's (2016) broader consideration from their chapter, "The inheritance of next generation engaged scholars", published in Publicly engaged scholars: Next-generation engagement and the future of higher education. In the chapter, Saltmarsh and Hartley state, "the language of 'regimes' is significant; it is a language of power, privilege, and politics. It constructs an understanding of knowledge generation and of teaching and learning that is inherently political—with consequences for equity and justice in a democracy".

Within this context, it is helpful to define the competing regimes, prior to considering how they might inform our approach to the anchor mission strategy. The public good regime "reflects the dominant academic culture of higher education, often characterized as 'scientific,' 'rationalized,' and 'objectified,' meaning that the approach to public problems is predominantly shaped by specialized expertise 'applied' externally 'to' or 'on' the community, providing 'solutions' to what has been determined to be the community's 'needs"' (Saltmarsh \& Hartley, 2016). Arguably, Cisneros and Harkavy developed the basic principles of the "anchor institution" concept in 1995 under this regime.

The academic capitalist regime "values privatization and profit taking in which institutions, inventor faculty, and corporations have claims that come before those of the public," and holds that "knowledge is constructed as a private good, valued for creating streams of high-technology products that generate profits as they flow through global markets" (Slaughter \& Rhoades, 2004). For the purposes of this discussion, and the idea of the anchor mission strategy, we 
broaden this notion a bit beyond the concepts of technology transfer and intellectual property. We examine institutional investment strategies that are profit generating and maximizing. We consider also those cost-containment approaches that align with the business aspects of higher education.

Finally, the public-engagement knowledge regime, "comprises core academic norms determined by values such as inclusiveness, participation, task sharing, and reciprocity in public problemsolving, and an equality of respect for the knowledge and experience that everyone contributes to education, knowledge generation, and community building. [...] The university is part of an ecosystem of knowledge production addressing public problem-solving, with the purpose of advancing an inclusive, collaborative, and deliberative democracy" (Saltmarsh \& Hartley, 2016). Each of these regimes is advancing competing values, and norms, some of which will likely be prioritized in ongoing decision-making by senior-level leaders. In adopting an anchor mission strategy, leaders should recognize these regimes and their corresponding opportunities and challenges, as it would affect the character and public perception of the institution. Recognizing the innate tensions among the regimes, and the descriptive frameworks they are advancing as we consider our anchor mission strategies, will allow us to develop more meaningful and thoughtful questions, and subsequently pursue more aligned and intentional outcomes.

\section{Implications for the Anchor Mission Strategy}

Each of the regimes carries a lens through which decision-making may be occurring. Appropriately positioning the anchor mission strategy within ongoing academic conversations related to the public good, public engagement knowledge, and academic capitalist regimes, advances more nuanced considerations of the role of higher education within local communities.

Cisneros and Harkavy considered the idea of the anchor institution, and its subsequent mission, through the lens of the dominant academic culture of higher education at that time. This was the "public good" regime. The decades since have seen the emergence of the public-engagement knowledge regime, and the academic capitalist regimes. Therefore, we think it is important to address the anchor mission strategy within the context of these newer regimes as well. The anchor mission, as a community engagement strategy through which institutions engage their local communities, may face similar challenges to community engagement as a broader movement, particularly related to the impacts of the public good regime. As Butin (2012) states in his introduction to The Engaged Campus, feminist, critical, postcolonial, and critical race scholars

have questioned the grounding for just about every single assumption, enactment, and orientation of 'community' and 'engagement.' From the reification of 'the other' to a problematic ethical foundationalism to a distressing cultural voyeurism to a middling conceptual framework for organizational and community change, the community engagement movement currently lacks the depth of scholarship necessary to provide a solid base for its embrace across higher education.

Just as the broader notion of community engagement must wrestle with the competing regimes of higher education, so too must the anchor mission strategy understand itself within these frameworks. 
For example, the anchor mission strategy that aligns with the public engagement knowledge regime might consider a more bidirectional relationship with the broader community. This is similar to how a scholar might pursue their research within this framework: "the center of the engaged scholar's identity is a scholarship that commands recognition of personal and communal values over the narrow, academic-centric self-interests of traditional scholarship. This newer form of scholarship recognizes community-based expertise and is propelled by a desire for all people to realize their highest potential" (Dostilio, et. al, 2016). Considering community-based expertise within the anchor mission strategy will fundamentally change the dynamic and approach to operational decision-making processes as well as teaching and learning outcomes that result in more economic reciprocity with legacy residents.

As aforementioned, by broadening the nature of academic capitalism beyond research and technology transfer opportunities, scholars can develop more intentional and inclusive models for how to engage with the most marginalized communities. For example, how might universitysupported innovation and commercialization projects result in long-term wealth building opportunities for local underemployed residents? Alternatively, how can a university support venture-capital startups and smaller businesses that directly meet community needs? The anchor mission helps to unite these long-standing public good and business interest goals through intentionally developing place-based partnerships, justice-driven community benefit agreements and investments into shared equity enterprises.

It is evident that the anchor mission can realign operational and investment business practices and build better cohesion between local anchor partners around collective impact goals. Administrators, staff, faculty, students, and alumni with local community members can intentionally build capacity of local businesses, securing family-supporting employment opportunities, increasing the local tax-base, and developing a more environmentally sustainable supply chain. They can invest in worker-owned grocery stores in food deserts, to increase the core outcomes of higher education to be civically and workforce minded, while also supporting marketable knowledge innovations. Implementation of anchor mission strategies serve higher education's public mission by securing cradle-to-retirement pipelines for local residents, reducing brain drain, while strengthening community engagement and equity efforts in our most impacted neighborhoods.

There are clear tensions created when institutions of higher education engage their local communities, and as a result, there is a need for universities/communities to set clear expectations. What are the limits of the university to engage with the community - and how can the two clearly communicate and honestly call into question those boundaries, in a way that builds trust? Both must recognize the realities of the capitalist culture in which we operate, the dominant and historical culture of the public good regime, and the more pragmatic idealism of the public engagement knowledge model, as well as the inherent tensions between the three. This helps to develop more nuanced communications with stakeholders inside and outside the institution to better practically address social and economic inequalities. The anchor mission strategy supports the different community engagement regimes in ways that can also positively impact community relations and academic outcomes. 


\section{References}

Alperin, J.P., Muñoz Nieves, C., Schimanski, L., Fischman, G.E., Niles, M.T. \& McKiernan, E.C. (2018, October 16). How significant are the public dimensions of faculty work in review, promotion, and tenure documents? Humanities Commons [preprint]. Retrieved from http://dx.doi.org/10.17613/M6W950N35

Benson, L., Harkavy, I., Puckett, J., Hartley, M., Hodges, R.A., Johnston, F.E., \& Weeks, J. (2017). Knowledge for social change: Bacon, Dewey, and the revolutionary transformation of research universities in the twenty-first century. Philadelphia, PA: Temple University Press.

Butin, D. (2012). When engagement is not enough: Building the next generation of the engaged campus. In D.W. Butin, \& S, Seider (Eds.) The engaged campus: Certificates, minors, and majors as the new community engagement. (pp. 1-11). New York: Palgrave MacMillan.

Cisneros, H.G., Harkavy, I., \& Foote, J. (1995, January 11). The university and the urban challenge. U.S. Department of Housing and Urban Development. Retrieved from https://www.nettercenter.upenn.edu/sites/default/files/1995_CisnerosThe $\% 20$ University $\% 20$ and $\% 20$ the $\% 20$ Urban $\% 20$ Challenge.pdf.

Dostilio, L.D., Janke, E., Miller, A., Post, M., \& Ward, E. (2016). Disrupting role dichotomies. In M.A. Post, E. Ward, N.V. Longo, \& John Saltmarsh (Eds). Publicly engaged scholars: Nextgeneration engagement and the future of higher education, (pp. 117-129). Sterling, VA: Stylus Publishing.

Giles, H. (2012). Negotiating the boundary between the academy and the community. In D.W. Butin \& S. Seifer (Eds). The engaged campus: Certificates, minors, and majors as the new community engagement (pp. 49-67). New York: Palgrave MacMillan.

https://doi.org/10.1057/9781137113283 4

Hodges, R. \& Dubb, S. (2012.). The Road Half Traveled: University Engagement at a Crossroads. East Lansing, MI: Michigan State University Press.

Slaughter, S., \& Rhoades, G. (2004) Academic capitalism and the new economy: Markets, the state, and higher education. Baltimore, MD: Johns Hopkins University Press.

Saltmarsh, J., \& Hartley, M. (2016). The inheritance of next generation engaged scholars. In M.A. Post, E. Ward, N.V. Longo, \& John Saltmarsh (Eds). Publicly engaged scholars: Nextgeneration engagement and the future of higher education, (pp. 15-33). Sterling, VA: Stylus Publishing. 


\section{Author Information}

*Daniel J. Bergen

Executive Director, Office of Community Engagement

Marquette University

PO Box 1881

Milwaukee, WI 53233

Telephone: 414-288-3033

Email: daniel.bergen@marquette.edu

Dr. Bergen graduated from Marquette University in British Literature, with a focus on cognitive literary theory and the Romantic era. He is the founding, and executive director of the Office of Community Engagement at Marquette University where he is responsible for the promotion, support, and advancement of community engagement in research, teaching, and service. He is a member of the National Forum for Chief Engagement Officers, university co-representative for the Higher Education Anchor Mission Initiative, member of the Southeastern Wisconsin Regional Community Engagement Steering Committee, and member of the Near West Side Partners, a Milwaukee-based anchor mission collaborative between Marquette University, MillerCoors, Harley Davidson, Aurora Health Care, and Potawatomi Business Development Corporation.

\section{Emily Sladek}

Manager of Higher Education Engagement

The Democracy Collaborative

120018 th Street NW, Suite 1225

Washington, DC 20036

Telephone: (202) 559-1473 x127

Email: esladek@democracycollaborative.org

Ms. Sladek is the Manager of Higher Education Engagement at the Democracy Collaborative. She leads the Collaborative's higher education programming and in partnership with the Coalition of Urban and Metropolitan Universities, manages the Higher Education Anchor Mission Initiative that includes over 30 public and private universities and colleges from across North America. She earned a Master of Public Administration from The Evergreen State College with a focus on research and evaluation for academic bridge programs (TRiO) as well as the Gateways for Incarcerated Youth program, which provides education pathways to youth in the juvenile offender system. Previously, she interned with the Peace Economy Transitions program at the Institute of Policy Studies identifying best practices in community-led economic development in converting the defense industry to civilian uses.

\footnotetext{
*Corresponding author
} 